\title{
Increase in the prevalence of health anxiety in medical clinics: possible cyberchondria
}

\begin{tabular}{|c|c|}
\hline Journal: & International Journal of Social Psychiatry \\
\hline Manuscript ID & ISP-19-0103.R1 \\
\hline Manuscript Type: & Original Article \\
\hline $\begin{array}{r}\text { Date Submitted by the } \\
\text { Author: }\end{array}$ & $n / a$ \\
\hline Complete List of Authors: & $\begin{array}{l}\text { Tyrer, Peter; Imperial College London, Centre for Psychiatry } \\
\text { Tyrer, Helen; Imperial College London, Centre for Psychiatry } \\
\text { Cooper, Sylvia; Imperial College London, Centre for Psychiatry } \\
\text { Wang, Duolao; Liverpool School of Tropical Medicine, Statistics } \\
\text { Bassett, Paul ; Amersham, Buckinghamshire }\end{array}$ \\
\hline Keywords: & health anxiety, cyberchondria, prevalence, medical patients \\
\hline Abstract: & $\begin{array}{l}\text { Background: } \\
\text { Health anxiety may be an increasing problem because of the focus on } \\
\text { monitoring health and increasing use of the internet for self-diagnosis } \\
\text { (cyberchondria). There is very little information about changes in the } \\
\text { prevalence of health anxiety. } \\
\text { Aims: We compared the prevalence of health anxiety in four medical } \\
\text { clinics in one hospital over a four year period using the Health Anxiety } \\
\text { Inventory (HAI) as a diagnostic marker. } \\
\text { Method: } \\
\text { Patients attending cardiology, endocrine, gastroenterology, and } \\
\text { respiratory medicine clinics at Kings Mill Hospital, North } \\
\text { Nottinghamshire, completed the HAI while waiting for their } \\
\text { appointments. There were eight research assistants involved in collecting } \\
\text { data, two in the } 2006-8 \text { period and six in the } 2008-10 \text { period. As a } \\
\text { consequence more data were collected on the second occasion. } \\
\text { Results: } \\
\text { There was an increase in the prevalence of health anxiety from } 14.9 \% \text { in } \\
2006-8 \text { ( } 54 \text { positive of } 362 \text { assessed) to } 19.9 \% \text { (1132 positive out of } \\
5704 \text { assessed) in } 2008-10 \text {. This increase was primarily noted in } \\
\text { gastroenterology clinics (increase of } 10 \% \text { ) and not shown in endocrine } \\
\text { ones. } \\
\text { Conclusion: } \\
\text { The prevalence of health anxiety is increasing in those who attend } \\
\text { medical out-patient clinics. Reasons are given that this may be a } \\
\text { possible result of cyberchondria, as the excessive use of the internet to } \\
\text { interpret troubling symptoms is growing. Further studies are needed in } \\
\text { other populations, but there is reason to be concerned at this trend as it } \\
\text { is likely to increase the number of medical consultations unnecessarily. }\end{array}$ \\
\hline
\end{tabular}

\section{SCHOLARONE" Manuscripts}




\section{Background:}

Health anxiety may be an increasing problem because of the focus on monitoring health and increasing use of the internet for self-diagnosis (cyberchondria). There is very little information about changes in the prevalence of health anxiety.

Aims: We compared the prevalence of health anxiety in four medical clinics in one hospital over a four year period using the Health Anxiety Inventory (HAI) as a diagnostic marker.

\section{Method:}

Patients attending cardiology, endocrine, gastroenterology, and respiratory medicine clinics at Kings Mill Hospital, North Nottinghamshire, completed the HAI while waiting for their appointments. There were eight research assistants involved in collecting data, two in the 2006-8 period and six in the 2008-10 period. As a consequence more data were collected on the second occasion.

\section{Results:}

There was an increase in the prevalence of health anxiety from $14.9 \%$ in 2006-8 (54 positive of 362 assessed) to 19.9\% (1132 positive out of 5704 assessed) in 2008-10. This increase was primarily noted in gastroenterology clinics (increase of 10\%) and not shown in endocrine ones.

\section{Conclusion:}

The prevalence of health anxiety is increasing in those who attend medical out-patient clinics. Reasons are given that this may be a possible result of cyberchondria, as the excessive use of the internet to interpret troubling symptoms is growing. Further studies are needed in other populations, but there is reason to be concerned at this trend as it is likely to increase the number of medical consultations unnecessarily. 


\title{
Increase in the prevalence of health anxiety in medical clinics: possible cyberchondria
}

\author{
Peter Tyrer ${ }^{1}$, Sylvia Cooper ${ }^{1}$, Helen Tyrer ${ }^{1}$, Duolao Wang ${ }^{2} \&$ Paul Bassett $^{3}$ \\ ${ }^{1}$ Centre for Psychiatry, Imperial College, London \\ 2 Department of Statistics, Liverpool School of Tropical Medicine, Liverpool, UK \\ ${ }^{3}$ Independent Statistical Consultant, Amersham, UK
}

\section{Background:}

Health anxiety may be an increasing problem because of the focus on monitoring health and increasing use of the internet for self-diagnosis (cyberchondria). There is very little information about changes in the prevalence of health anxiety.

Aims: We compared the prevalence of health anxiety in four medical clinics in one hospital over a four year period using the Health Anxiety Inventory (HAl) as a diagnostic marker.

\section{Method:}

Patients attending cardiology, endocrine, gastroenterology, and respiratory medicine clinics at Kings Mill Hospital, North Nottinghamshire, completed the HAl while waiting for their appointments. There were eight research assistants involved in collecting data, two in the 2006-8 period and six in the 2008-10 period. As a consequence more data were collected on the second occasion.

\section{Results:}

There was an increase in the prevalence of health anxiety from $14.9 \%$ in $2006-8$ ( 54 positive of 362 assessed) to $19.9 \%$ (1132 positive out of 5704 assessed) in 2008-10. This increase was primarily noted in gastroenterology clinics (increase of $10 \%$ ) and not shown in endocrine ones.

\section{Conclusion:}

The prevalence of health anxiety is increasing in those who attend medical outpatient clinics. Reasons are given that this may be a possible result of cyberchondria, as the excessive use of the internet to interpret troubling symptoms is growing. Further studies are needed in other populations, but there is reason to be concerned at this trend as it is likely to increase the number of medical consultations unnecessarily. 
The diagnosis of health anxiety is a relatively new concept. It is often regarded as a synonym for hypochondriasis, but it is not exactly the same. Although there continues to be some dispute over the subject, health anxiety can probably be regarded as anxious hypochondriasis and is best construed as an anxiety disorder (Scarella et al, 2016; Tyrer, 2018), although there is overlap with obsessional disorders (Stein et al, 2016). It has a more restricted definition than hypochondriasis, as this describes the primary preoccupation with having a disease. It includes considerable depressive pathology, sometimes to the point of delusions, expressed most severely as Cotard's syndrome (Berrios \& Luque, 1999).

The best equivalent of health anxiety is the diagnosis of illness anxiety in DSM-5, which includes the anxious preoccupation with either having, or in danger of having, a currently undiagnosed medical illness, in which the distress is created not by physical symptoms but by anxiety about their disease implications (American Psychiatric Assocation, 2013). In the forthcoming ICD-11 classification health anxiety is included under the general diagnosis of hypochondriasis, not very different from that in DSM-5 but including ' catastrophic misinterpretation of bodily signs or symptoms' as a feature, which is not always present in people with abnormal health anxiety.

The most likely estimate of its prevalence in the community comes from the Australian National survey in which figures of $6.3 \%$ for lifetime prevalence and 3.5\% for current prevalence were found (Sunderland et al, 2013). This can be regarded as a baseline figure only, and there are suspicions that the condition is increasing in prevalence because of general guidance to people to monitor their own health with the help of apps (Parker et al, 2016) and the growing use of the internet and social media to advise and diagnose symptoms (Starcevic and Aboujaoude, 2015), including cyberchondria, the repeated use of the internet to 
diagnose symptoms unnecessarily, which is very closely linked to health anxiety (Fergus and Russell, 2016), and which has been shown to increase its severity and persistence (Doherty-Torstrick et al, 2016). But, despite these suspicions, currently there is no good evidence that the prevalence of health anxiety is increasing and in the current research of our group we had an opportunity to evaluate this.

\section{Method}

\section{Participants}

The patients invited to take part in both of these studies were all attending cardiology, respiratory medicine, gastroenterology and endocrinology clinics at Kings Mill Hospital, North Nottinghamshire, UK. This is a general hospital that is fairly typical of general hospitals in the NHS. The patients in each study were assessed for health anxiety but seen for different purposes. The first study was a preliminary one to assess the relationship between health anxiety and other somatic symptoms by comparing scores on a standard scale for assessing health anxiety (Short Health Anxiety Inventory)(Salkovskis et al, 2002) and a new one for assessing unexplained symptoms (Schedule for Evaluating Persistent Symptoms (SEPS)(Tyrer et al, 2013). Patients attending cardiology, respiratory medicine, endocrine and gastrointestinal clinics were selected in the study. There were only a few part-time research assistants available in this study and they visited clinics on an ad hoc basis over a period of 24 months (August 2006July 2008). The timing of their visits was organised so that all relevant clinics were covered during the course of the study. 
The second study was carried out as a large randomised controlled trial of the efficacy of an adapted form of cognitive behaviour therapy in the treatment of health anxiety, the CHAMP study (Tyrer et al, 2011a, 2011b, 2014), in which patients were recruited over 20 months between October 2008 and July, 2010. In this study there were many more research staff and they aimed to assess the majority of patients attending cardiology, respiratory medicine, neurological, endocrine and gastroenterology out-patient clinics at King's Mill Hospital (and five other hospitals across England). For the purposes of the current study only those attending King's Mill Hospital were considered.

In both studies patients attending were invited to complete the Short Health Anxiety Inventory (SHAI)(Salkovskis et al, 2002) to identify those who probably had a significant degree of health anxiety (a score of 20 or more, now accepted as an accurate threshold (Hedman et al, 2015). Those that scored below this threshold were not seen again, and the those who scored above the threshold were interviewed again to determine the feasibility of taking part in the full randomised controlled trial. In the second study patients attending neurological clinics were also seen but they were excluded from the two study comparison. Ethical approval was given by the Derbyshire Research Ethics Committee (06/Q2401/130) for the first study (2006-7), and by the North Nottingham Research Ethics Committee (08/H0403/56) for the second.

\section{Results}

362 patients were screened in the first study and 5704 in the second (Table). The difference can largely be explained by the research time available for assessment. This was 10 times more (30 hours vs 3 hours per week) in study 2 than in study 1. 
The mean \pm standard deviation HAl scores for each of the clinics and in total are shown (Table ).

\begin{tabular}{|l|l|l|l|l|l|l|}
\hline Clinic type & $\begin{array}{l}\text { Study 1: } \\
\text { Screened }\end{array}$ & $\begin{array}{l}\text { Study 1: } \\
\text { number } \\
\text { with HAI } \\
(\%)\end{array}$ & $\begin{array}{l}\text { Study 2: } \\
\text { Screened }\end{array}$ & $\begin{array}{l}\text { Study 2: } \\
\text { number } \\
\text { with HAl } \geq 20 \\
(\%)\end{array}$ & $\begin{array}{l}\text { Change in } \\
\% \text { of } \\
\text { health } \\
\text { anxiety }\end{array}$ & Significance \\
\hline Cardiology & 122 & $21(17.2)$ & 1877 & $396(21.1)$ & +3.9 & 0.30 \\
\hline Endocrinology & 21 & $6(28.6)$ & 1691 & $345(20.4)$ & -8.2 & 0.36 \\
\hline $\begin{array}{l}\text { Gastro- } \\
\text { enterology }\end{array}$ & 132 & $15(11.4)$ & 762 & $165(21.7)$ & +10.3 & 0.0065 \\
\hline $\begin{array}{l}\text { Respiratory } \\
\text { Medicine }\end{array}$ & 87 & $12((13.8)$ & 1374 & $226(16.5)$ & +2.7 & 0.51 \\
\hline All clinics & 362 & $54(14.9)$ & 5704 & $1132(19.9)$ & +5 & 0.02 \\
\hline
\end{tabular}

TABLE Comparison of prevalence of health anxiety over time between 2005-8 (Study 1) and 2008-2010 (Study 2) at King's Mill Hospital, Notts in four medical clinics

\section{Discussion}

The results of this study are, we believe, the first to show an increase in the prevalence of health anxiety over a relatively short period. Although there have been many suspicions that health anxiety is becoming more frequent, partly because of cyberchondria, this is the first study to show a definite increase, even though it was only over a two year period and the increase was not dramatic. The main limitation of the findings is that the two studies were not pre-planned to be linked, but the clinics were identical and the use of the SHAl questionnaire obviated any question of bias. The SEPS scale used in the first study was a 
project to evaluate its psychometric properties and other instruments such as the Whitely Index might have been used if these studies had been linked in advance.

Although there was an overall increase in the prevalence of pathological health anxiety a significant increase was only shown in gastroenterology clinics. This may be related to the much wider use of colonoscopy and endoscopy in recent years and greater attention given to conditions such as irritable bowel syndrome. The level of health anxiety in these patients has been noted to be high and reassurance counter-productive (Gasteiger et al, 2018). This type of patient is likely to very frequent in gastroenterology clinics.

The other limitation that avoids general conclusions being drawn is that this study was carried out in medical out-patients, a population in which health anxiety is known to be highly prevalent (Tyrer et al, 2011), and so the results may not generalize to other populations.

One of the major concerns in the health services of today is the increasing focus of personal responsibility in monitoring health, and this is a proper subject o be addressed by social psychiatry, even though most of the people with this disorder present to general hospitals, not mental health services. Whilst the fundamental principles behind this are sound the dangers of unnecessary worry and concern have been insufficiently recognised. The consequence is unnecessary consultation, over-investigation and preventable suffering (Tyrer et al, 2015). Now that there are effective means of treating health anxiety that are cost-effective and long-lasting (Tyrer et al, 2017; Morriss et al, 2018) there is a 
need to redress the balance so that all practitioners become aware of the need to identify health anxiety before it becomes pervasive. The message of this paper is that the need for such an initiative is becoming urgent.

American Psychiatric Association. Illness Anxiety: in $5^{\text {th }}$ Revision of the Diagnostic and Statistical Manual for Mental Disorders. Washington, DC, p.215.

Berrios GE, Luque R. (1999). Cotard's "On hypochondriacal delusions in a severe form of anxious melancholia". History of Psychiatry, 10, 269-78.

Doherty-Torstrick ER, Walton KE, Fallon BA. (2016). Cyberchondria: parsing health anxiety from online behavior. Psychosomatics, 57, 390-400.

Fergus T,A., Russell, L.H. (2016). Does cyberchondria overlap with health anxiety and obsessive-compulsive symptoms? An examination of latent structure and scale interrelations. Journal of Anxiety Disorders, 38, 88-94.

Gasteiger, C., Sherriff, R., Fraser, A., Shedden-Mora, M.C., Petrie, K.J., Serlachius, A.S. (2018). Predicting patient reassurance after colonoscopy: The role of illness beliefs. Journal of Psychosomatic Research,114, 58-66.

Hedman, E., Lekander, M., Ljótsson, B., Lindefors, N., Rück, C., Andersson, G., et al(2015). Optimal cut-off points on the Health Anxiety Inventory, Illness Attitude Scales and Whiteley Index to identify severe health anxiety. PLoS One, 10, e0123412.

Morriss, R., Patel, S., Malins, S., Guo, B., Higton, F., James, W., Wu, M., Brown, P., Boycott, N., Kaylor-Hughes, C., Morris, M., Rowley, E., Simpson, J., Smart, D., Stubley, M., Kai, J., \& Tyrer, H. (2019). Clinical and economic outcomes of remotely delivered cognitive behaviour therapy versus treatment as usual for repeat unscheduled care users with severe health anxiety: a multicentre randomised controlled trial. BMC Medicine, 17, 16.

Parker, L., Bero, L., Gillies, D., Raven, M., Mintzes, B., Jureidini, J., et al. (2018).Mental health messages in prominent mental health Apps. Annals of Family Medicine, 16, 338-342.

Salkovskis, P.M., Rimes, K.A., Warwick, H.M.C., Clark, D.M. (2002). The Health Anxiety Inventory: development and validation of scales for the measurement of health anxiety and hypochondriasis. Psychological Medicine, 32, 843-853. 
Scarella, T.M., Laferton, J.A., Ahern, D.K., Fallon, B.A., Barsky, A. (2016). Therelationship of hypochondriasis to anxiety, depressive and somatoform disorders. Psychosomatics, 57, 200-207.

Starcevic, V., Aboujaoude, E. (2015). Cyberchondria, cyberbullying, cybersuicide, cybersex: "new" psychopathologies for the 21st century? World Psychiatry, 14, 97-100.

Stein, D.J., Kogan, C.S., Atmaca, M., Fineberg, N.A., Fontenelle, L.E., Grant, J.E. et al (2016). The classification of obsessive-compulsive and related disorders in the ICD-11. Journal of Affective Disorders, 190, 663-674.

Sunderland, M., Newby, J.M. \& Andrews, G. (2013). Health anxiety in Australia: prevalence, comorbidity, disability and service use. British Journal of Psychiatry, 202, 56-61.

Tyrer, P. (2018). Recent advances in the understanding and treatment of health anxiety. Current Psychiatry Reports, 20, 49.

Tyrer, H., Ali, L., Cooper, F., Seivewright, P., Bassett, P, \& Tyrer, P. (2013). The Schedule for Evaluating Persistent Symptoms (SEPS): a new method of recording medically unexplained symptoms. International Journal of Social Psychiatry, 59, 281-287.

Tyrer, P., Cooper, S., Tyrer, H., Salkovskis, P., Crawford, M., Green, J. et al. (2011a). CHAMP: Cognitive behaviour therapy for health anxiety in medical patients: a randomised controlled trial. BMC Psychiatry, 11:99.

Tyrer, P., Cooper, S., Crawford, M., Dupont, S., Green, J., Murphy, D., Salkovskis, P., Smith, G., Wang, D., Bhogal, S., Keeling, M., Loebenberg, G., Seivewright, R., Walker, G., Cooper, F., Evered, R., Kings, S., Kramo, K., McNulty, A., Nagar, J., Reid, S., Sanatinia, R., Sinclair, J., Trevor, D., Watson, C., Tyrer, H. (2011b). Prevalence of health anxiety problems in medical clinics. Journal of Psychosomatic Research, 71, 392-394.

Tyrer, P., Cooper, S., Salkovskis, P., Tyrer, H., Crawford, M., Byford, S., et al (2014). Clinical and cost-effectiveness of cognitive behaviour therapy for health anxiety in medical patients: a multicentre randomised controlled trial.. Lancet, $383,219-225$.

Tyrer, P., Eilenberg, T., Fink, P., Hedman, E., \& Tyrer, H. (2016). Health anxiety: the silent disabling epidemic. BMJ, 353, i2250. 
Tyrer, P., Salkovskis, P., Tyrer, H., Wang, D., Crawford, M.J., Dupont, S., et al. (2017). Cognitive behaviour therapy for health anxiety in medical patients (CHAMP): randomised controlled trial with outcomes to five years. Health Technology Assessment, 21, 50. 